\title{
3. OTROS ARTICULOS
}

\section{LOS PROBLEMAS DE LEGALIDAD Y LA LEGITIMIDAD DEL SINDICALISMO} COLOMBIANO: UNA APROXIMACION HISTORICA

\author{
Medófilo Medina (*)
}

\section{INTRODUCCION}

Cualquier definición de legitimidad asocia dicho concepto a categorias tales como aceptación, consenso, consentimiento. Queremos mediante un rápido recorrido histórico examinar el peso que han tenido la concertación y la coerción en el sistema de interacciones entre el movimiento sindical por un lado, y el Estado y la Sociedad civil por el otro. Problemas como el que aquí se señala tienen hoy particular pertinencia por cuanto se ha adoptado una nueva Constitución que en varios aspectos consagra un orden más abierto y democrático que el establecido por la Constitución de 1886.

\section{EL SURGIMIENTO DEL}

\section{SINDICALISMO: EL DIFICIL COMBATE POR LA LEGITIMIDAD}

De la clase obrera colombiana puede hablarse desde comienzos del siglo veinte. Al iniciarse el segundo decenio pueden identificarse los que serían los grupos típicos del proletariado: jornaleros de las haciendas cafeteras, trabajadores de la construcción de las vías de comunicación, braceros del río Magdalena, obreros de los enclaves extranjeros (petróleo, banano), un sector socialmente abigarrado y numeroso, integrado por operarios de pequeñas empresas artesanales y por trabajadores de la construcción. Existía también un grupo ciertamente minoritario de obreros de la moderna industria fabril.

¿Qué tipo de relaciones se establecieron entre estos trabajadores y el Estado? En los análisis históricos sobre 1os trabajadores en América Latina ha tomado la solidez del lugar comun la aceptación de una periodización conformada por dos etapas: la primera, asociada a un sindicalismo heróico, no regulado por normas jurídicas, con una disposición revolucionaria y la segunda caracterizada por la cooptacion" del movimiento obrero por parte del Estado burgués.

El período revolucionario se extiende desde finales del siglo XIX hasta la crisis de 1929 - 1932. La etapa de la cooptación o de predominio del reformismo empieza en los desarrollos mismos de la crisis y se prolonga hasta ahora (1).

Ante esa manera de periodizar la historia sindical, parece más conveniente y con mayores posibilidades explicativas el punto de vista de otro especialista sobre el movimiento sindical: Ian Roxboroush, quien señala que la incorporación no se realiza una vez y para siempre. Es un asunto que está sujeto a una periódica renegociación. Así mismo, en la relación entre patronos y sindicatos y entre éstos y el Estado, son replanteados en coyunturas diversas los problemas del consenso, la legitimidad y la hegemonía (2).

En febrero de 1910 se llevó a cabo una huelga de braceros del río Magdalena que comprometió a trabajadores de diversos puertos de esa arteria fluvial. El alza de salarios fué la reivindicación central. En ese cese de actividades que permite hablar por primera vez en Colombia de movimiento huelguístico en la medida en que un conflicto suscita una protesta en cadena, se notan dos rasgos que serán característicos de la actividad huelguística hasta los años treinta: primero, la apelación a la violencia por parte de los trabajadores; segundo, la potencialidad de un conflicto para involucrar a trabajadores de otras ramas en movimientos similares.

\footnotetext{
(*). Historiador, Profesor Asociado de la Universidad Nacional de Colombia. Bogotá.

(1). Este tipo de periodización ha sido sustentado para la historia laboral de los países de América Latina por Hobart Spalding, entre otros Organized Labor in Latin America (New York, 1977 ) En Colombia se ha suscrito el mismo enfoque: Otros en dos trabajos: Manuel Moncayo, Fernando Roja, Luchas Obreras y Política Laboral en Colombia Medellín, 1978 Daniel Pecaut,Política y Sindicalismo

(2). Ian Roxborouh, Comparative Labour movements (Versión de 18 de junio de 1987)
} 
A comienzos de 1918 y finales de 1919 se producen nuevos auges huelguísticos en 1 os cuales mantienen la iniciativa 1 os trabajadores de las comunicaciones y el transporte. Luego, de 1923 en adelante se ampliará el espectro de 1 os sectores obreros que se involucran en huelgas. En éstas toman parte los asalariados de 1os "enclaves extranjeros" (banano, petróleo). Esta agitación corre pareja con la aceleración de los ritmos del crecimiento capitalista vinculado a fenómenos tales como la expansión cafetera, la política de endeudamiento externo, las inversiones en los "enclaves" y el pago de 25 millones de dólares por parte de los Estados Unidos por concepto de la indemnización por la intervención en Panamá.

Al principio, 1os gobiernos de la llamada Hegemonía Conservadora articulan frente a la protesta obrera una política en la que se mezclan la mano dura y el paternalismo. Desde 1924 la represión se convierte en la única alternativa oficial con respecto a las huelgas y a la movilización social. En concordancia con la anterior situación el Ministerio de Guerra asume la "solución" por la fuerza de los conflictos. Esto se correspondía con el enfoque gubernamental según el cual las diferencias entre trabajadores y patronos debían resolverse dentro de las empresas. Si salían de ese ámbito tales conflictos se los trataba como problemas de orden público.

No existía un marco normativo que regulara jurídicamente las relaciones de trabajo. Empresarios y funcionarios del Estado le negaban toda legitimidad a los movimientos reivindicativos, los cuales eran descritos como el producto de la intervención de "fuerzas extrañas" ajenas a la tradición nacional. La presencia de algunos dirigentes obreros de origen extranjero, presencia por demás insignificante si se la contrasta con la masiva afluencia de inmigrantes extranjeros a otros países de América Latina, era presentada como demostración de esa tesis.

La respuesta favorable del gobierno a las exigencias de represión de los patronos en el caso de las huelgas en las empresas pertenecientes al capital extranjero ponían al desnudo el verdadero alcance de esas argumentaciones. En enero de 1927 el Ministro de Guerra, Ignacio Renjifo, declaraba en relación con las huelgas de apoyo a los trabajadores de la Tropical Oil Company que no podía atenderse ninguna solicitud de negociación, dado que quienes las formulaban no eran oficialmente huelguistas "ya que se niegan a trabajar con el único fín de solidarizarse con los obreros rebeldes de Barranca y de hostilizar a una nación amiga de Colombia" (3).

La huelga de los trabajadores bananeros de la United Fruit Company terminó con una brutal masacre cuyos alcances cuantitativos en vidas no se han establecido aún. En esa huelga de diciembre de 1928 el gobierno puso las armas oficiales prácticamente a órdenes del gerente de la United. El gobierno tenía un profundo temor a malquistarse con el Departamento de Estado norteamericano que a su turno actuaba como solícito protector de 1 os intereses y prerrogativas de las companías norteamericanas. Por ese camino el gobierno esperaba mantener el flujo de los empréstitos.

Así culminó la primera etapa del movimiento sindical en medio de una aguda represión y sin que este hubiera avanzado sensiblemente en la conquista de su legitimidad política. No resultaba exagerado el tono de un informe que un dirigente obrero presentaba en 1930: "Hoy por hoy, no existen sindicatos sino pequeños núcleos o fracciones que sostienen el fuego revolucionario de la lucha de clases. Los sindicatos que existieron hasta los años 28 y 29 han sido disueltos por la reacción gubernamental y la crisis económica. Hay trescientos presos de nuestra causa desde julio de 1929". Dicho informe concluía con esta expresiva sentencia: "Las masas han sido secuestradas por la burguesía" (4).

\section{LEGITIMIDAD EFIMERA: 1930-1945}

Desde comienzos de los años treinta diversos núcleos obreros desplegaron una acción sistemática encaminada a la reconstrucción de las pocas organizaciones sindicales que habían sido creadas en los dos decenios anteriores y a la fundación de otras nuevas. Se destaca como novedad el empeño puesto en la creación de organismos que pudieran coordinar la acción de los sindicatos dispersos: federaciones locales y una confederación nacional. Aunque los éxitos en este último aspecto se mostraban esquivos, los esfuerzos tuvieron continuidad. Ello en no poca medida se vinculaba a la presencia en la escena pública de nuevas fuerzas políticas para las cuales la existencia de una ramificada organización gremial de los trabajadores constituía una garantía de su propio desarrollo. Esas formaciones políticas fueron el Partido Comunista y la UNIR (5), fundado el primero en 1930 y la segunda a finales de 1933 por el caudillo liberal Jorge Eliecer Gaitán.

En Colombia los grupos dirigentes buscaron superar los efectos de la crisis económica por el camino del reformismo. Una combinación de sectores dominantes en la cual prevalecían los intereses burgueses impusieron la alternativa mediante el ascenso al poder del partido liberal en febrero de 1930. El primer gobierno de este período, el del presidente Enrique Olaya Herrera introdujo algunas novedades, una de ellas fue el reconocimiento y la reglamentación de los sindicatos (Ley 83 de 1937). Hasta entonces, la forma típica moderna de organización de los trabajadores no tenía lugar alguno en el marco normativo del país.

El reformismo fue asumido con más decisión en la presidencia de Alfonso López Pumarejo (1934-1938). Durante esta administración se estableció una virtual alianza entre el gobierno y los obreros organizados. Estos apoyaron al primero en su curso reformista y el gobierno se avino a convertir a

\footnotetext{
(3). El Espectador, Bogotá, 28 de enero de 1927.

(4) Citado por Ignacio Torres Giraldo Los Inconformes, Ed. Margen Izquierda, Bogotá, 1974, t.IV, pág 182

(5) Unión Nacional Izquierdista Revolucionaria.
} 
la direccion sindical y sus asesores en interlocutores políticos en representación no solo de los afiliados sino del pueblo en general. La posibilidad de esa relación se veía favorecida por la agresiva oposición del partido conservador a las reformas.

La conducta de los políticos conservadores expresaba la disposición beligerante de terratenientes, Iglesia y algunos industriales. La alianza de la derecha presentaba al Frente Popular en España como la encarnación del mal que también amenazaba a Colombia por culpa del Presidente de la Republica. El de 1936 fue un año agitado en extremo. Justamente la celebración del primero de mayo fue convertida por los trabajadores en ocasión de apoyo al presidente López. Las grandes movilizaciones de ese día contribuyeron a mermar el ímpetu de la derecha y le restituyeron al gobierno una cierta libertad de maniobra. En agosto de 1936 se creó una central obrera nacional, la Confederación de Trabajadores de Colombia, C.T.C., que persistiría en la condición de central única hasta 1946.

La CTC fue el producto más claro de la concertación entre gobierno y trabajadores. En este periodo el sindicalismo se comprometió a fondo en orientar sus fuerzas hacia la presión política. Quizá eso explique el que la CTC tuviera acogida entre los trabajadores de los servicios públicos y en aquellos renglones desde los cuales resultaba más fácil la presión política. En las empresas industriales la confederación tuvo una presencia débil

El juego político de 1 os sindicatos y el fortalecimiento organizativo de los trabajadores alarmó a los patrones y a otros círculos sociales cuyos miembros no sólo se ubicaban en el partido conservador sino también en el liberal. Ahora se quería excluir al sindicalismo del sistema político o relegarlo a su periferia. Las justificaciones "doctrinarias" de ese empeño se buscaron como arriba se señaló en las campañas contra el Frente Popular Espanol, y contra la Internacional Comunista.

La operación encaminada a despojar de legitimidad al sindicalismo se adelantaba con la misma falta de imaginación del período anterior: el estribillo de "las fuerzas extrañas". Para no pocos dirigentes del partido liberal los únicos espacios aceptables, "naturales" de definición política de los trabajadores eran el liberalismo, en primer lugar y el apoliticismo, en el segundo. Para 1os conservadores lo único que podía rescatar a los sindicatos de la zona de sospecha era la dirección de la Iglesia Católica. Esto tenía acogida en sectores de la opinión de un país, por entonces abrumadoramente católico

Pronto el esquema de concertación se debilitó. Los dirigentes del Estado se empeñaron en recuperar el terreno supuestamente cedido a los sindicatos. La CTC respondió a esa estrategia con una cierta radicalización. Sin embargo, en función de la presión de los dirigentes liberales, no pocos de los líderes obreros estuvieron dispuestos a practicar la división de su propia central. La prueba de fuerza tuvo lugar en diciembre de 1945. Entonces la Federación de los trabajadores del rio Magdalena FEDENAL, declaró una huelga que fue al punto declarada ilegal por el gobierno liberal del presidente
Alberto Lleras Camargo. Según éste, no resultaba aceptable gue hubiese dos gobiernos, uno en Bogotá y el otro en el río Magdalena. El juicio presidencial constituyó una especie de patente de corso otorgada a los patronos de las empresas de navegación fluvial, quienes pasaron a sancionar a los huelguistas, al paso que los huelguistas eran sometidos militarmente.

El golpe asestado a FEDENAL, debilitó de manera muy notable a la CTC, de la cual era la federación mas poderosa. El sistema político mostro su incapacidad de aceptar al sindicalismo como un factor independiente. Así, la concertación tuvo una breve duración. A mediados de 1 os cuarenta el sindicalismo fue desprovisto de los títulos de legitimidad con que contó de manera episódica .

\section{EL SINDICALISMO Y LA VIOLENCIA 1946-1957}

Entre 1946 y 1957 Colombia vivió la Violencia, proceso caracterizado por una intensa confrontación política entre liberales y conservadores que dejó un saldo de 200.00 muertos caídos en una guerra civil no declarada". Ese proceso que desde comienzos de los años ochenta se ha llamado la "primera violencia" para distinguirla de la etapa de violencia que azota de nuevo a Colombia, desde mediados de los años ochenta incorporó los más diversos conflictos y escenarios. Sin embargo la primera violencia tiende a ser identificada globalmente con el enfrentamiento sectario entre liberales y conservadores y suele asociarsela a los acontecimientos que se desarrollaron en los campos. Es cierto que fue en las comunidades rurales donde se produjeron los hechos más crueles y donde fueron involucrados en el conflicto sectores muy numerosos de la población. Sin embargo el proceso mismo empezó en las ciudades.

Desde el punto de vista histórico y macrosocial el período de la violencia aparece como un verdadero proyecto de restauración política autoritaria frente al período precedente reformista y democrático.

El decenio de la postguerra fue un tiempo de intenso crecimiento de la economía colombiana en todos 1 os sectores. La industrialización que venía avanzando de manera espontánea se hizo objeto de una verdadera estrategia nacional. El dinamismo económico elevó en los empresarios las espectativas de ganancia. Los hombres de negocios, los inversionistas tenían la conciencia a mediados de los años cuarenta, de estar ante una fase nueva de acumulación. Los sindicatos, la intervención del Estado en la regulación de las relaciones obrero-patronales eran vistos como serios obstáculos para la marcha victoriosa del desarrollo económico.

Las élites impulsaron iniciativas en el sentido del desmonte de la ideología de la intervención estatal. Al tiempo se rodeó a la CTC de una atmósfera de sospecha. El presidente Lleras Camargo habló de "los abusos de las organizaciones sindicales" y agregó: "La explotación sin verguenza de las facilidades ofrecidas por las leyes sirve 
sólo para frenar el desarrollo progresivo de la política social" (6). Como en épocas anteriores, también en está, la campaña de deslegitimación del sindicalismo comenzó desde el gobierno.

Al subir al poder el partido conservador en 1946, se desplazó todo el apoyo al sindicalismo confesional orientado por la Iglesia en general y por miembros de la Compañia de Jesús, en particular. Ese sindicalismo había permanecido muy activo y durante años trabajó en silencio. Si a los gobiernos conservadores resultaba atractivo el confesionalismo en los sindicatos, para los empresarios resultaba no menos conveniente un sindicalismo que rechazaba su participación en política y que aceptaba como único marco de negociación el interior de la empresa. Ese sindicalismo de nuevo tipo recibió su concreción en la creación de la Unión de Trabajadores de Colombia, UTC, el 11 de junio de 1946. Esta central se constituyó con base en sindicatos agrícolas del centro del país y en sindicatos de la industria manufacturera del departamento de Antioquia.

En el clima de terror reinante durante la Violencia, los sindicatos independientes estuvieron bajo la ofensiva gubernamental y patronal en un proceso que pasó desapercibido por cuanto el drama de los campos: éxodos, masacres, homicidios con sevicia, monopolizaban la atención. En el período que estamos analizando desaparecieron las huelgas, muchos sindicatos se disolvieron, en algunas empresas importantes numerosos trabajadores fueron despedidos y los gobiernos miraron con satisfacción estos resultados. Sin embargo, todo ello contribuyó de manera fundamental a la extensión de la violencia, cuando se privó a sectores amplios de la sociedad de canales de expresión y organización.

Este estado de cosas de orden nacional se veía reforzado por las circunutancias de orden internacional. La Guerra Fría se tradujo en el estímulo por parte de los Estados Unidos en Latinoamérica a los regímenes dictatoriales o autoritarios. En Colombia entre el Partido Conservador en el poder y la dirección del Partido Liberal en la oposición, se produjo una peculiar emulación sobre cual de las dos formaciones políticas podía aparecer más convincentemente pro-norteamericana

El Partido Liberal tomó como campo de demostración de su anticomunismo su actitud ante los sindicatos. Expresiva de tal disposición es la conducta liberal ante la CTC que para finales de los años cuarenta se encontraba ya muy debilitada. En mayo de 1950 se realizó el X Congreso de la CTC. La dirección del Partido Liberal y el diario EL TIEMPO afín al mismo partido, pusieron todo su empeño en lograr la exclusión de las filas de la CTC de los sindicatos influidos por el Partido Comunista. Para lograr tal objetivo, era preciso partir en dos la organización por cuanto las fuerzas liberal y comunista eran equiparables en la CTC. En una declaración de la direccion liberal en vísperas del X
Congreso se consignaba: "La Dirección Liberal considera de importancia vital, no solo para el propio partido sino también para el propio progreso de la organización sindical en Colombia, que el congreso sindical del 10 de mayo defina la posición de los sindicatos colombianos sobre este punto, afiliando la CTC a la Confederación Mundial de Sindicatos Libres y a la correspondiente organización que va a crearse en América próximamente sobre los mismos principios. Esta decisión envuelve, naturalmente, la de separarse de la CTAL, cuyas orientaciones y actividades han dejado de corresponder a los principios aquí enunciados" (7).

Resulta extraño que la dirección de un partido político decida manejar la agenda de un Congreso Sindical. La explicación de esta conducta se explica en parte en las declaraciones del subsecretario de Estado Eduard Miller en la "Conferencia internacional prodemocracia y libertad", convocada por varios partidos latinoamericanos entre los cuales estaba el Partido Liberal Colombiano y que se celebró en La Habana. El funcionario norteamericano hacía notar el crecimento de la ORIT, la organización continental de trabajadores auspiciada por los sindicatos norteaméricanos, y la continua declinación de la Central de Trabajadores de América Latina (CTAL) y llamaba a los partidos a profundizar ese desarrollo. Los liberales querian demostrar con hechos su participación activa en la política continental de los Estados Unidos (8).

De su décimo congreso salió la CTC dividida en dos confederaciones, dirigida una por los liberales y por los comunistas la otra. En el clima de violencia esas organizaciones pervivieron como dos aparatos burocráticos sin posibilidad de influir entre los trabajadores y menos de organizarlos para defender sus intereses económicos y sociales.

La extensión de la violencia condujo a una crisis del régimen conservador. En medio de las crisis, las Fuerzas Armadas se proyectaron como el único sector capaz de asegurar la superación de la situación de disolución del sistema político. El 13 de junio de 1953, el teniente general Gustavo Rojas Pinilla dió el golpe de estado mientras el presidente titular Laureano Gómez salía para España, donde fue acogido por Franco.

La dictadura militar no varió la represión a los sindicatos independientes y acentuó el anticomunismo. El régimen alentó la creación de una organización sindical oficial. El 23 de junio de 1954 se realizó el congreso constitutivo de la CNT, Central Nacional del Trabajo. Con el proyecto que tenía una clara inspiración peronista, el régimen buscaba la organización de una base social propia. El proyecto no prosperó por la ruda oposición de los partidos tradicionales de la Iglesia Católica y de la UTC. Cada una de esas fuerzas protestaba contra el proyecto oficial no porque abogará por

(7) El Tiempo, Bogotá, abril 25 de 1990

Ver M. Medina. Cuadernos de Historia del PCC. CEIS-INEDO, Bogotá, 1989, p.36.

(8) Se ha documentado bien la presión del Departamento de Estado sobre el Partido Liberal para la persecución a la CTC. Ver Eduardo Saenz Rovner: "Documentos sobre el X Congreso Nacional de la CTC en 1950 y la Persecución Sindical en Colombia" en Anuario Colombiano de Historia Social y de la Cultura, Universidad Nacional, Bogotá, números 18-19 de 1990-1991 pp 309-335. 
la organización obrera autónoma sino porque temía ver afectada su parcela de influencia sindical.

Al remontar el medio siglo se tiene el panorama de un sindicalismo agobiado por la persecución y la exclusión, mediatizado por el confesionalismo e intervenido por el gobierno.

\section{EL SINDICALISMO EN LOS AÑOS SESENTA Y SETENTA: LEGITIMACION PRECARIA}

En los años sesenta y setenta el espacio político en Colombia está definido por el Frente Nacional que sustituyó a la dictadura del General Rojas. El nuevo régimen fue posible por el acuerdo de los partidos liberal y conservador para gobernar el país mediante las instituciones de la paridad y la alternación (*). El Frente Nacional implicó el restablecimiento parcial de las instituciones de la democracia representativa. Las fuerzas políticas no bipartidistas quedaron por fuera de la posibilidad de gozar de representación política propia y de ocupar cargos en el sector público.

El sindicalismo se propuso aprovechar los factores democráticos para abrir una etapa nueva de su desarrollo. Desde comienzos de los años sesenta la UTC se convirtió en la organización mayoritaria, la CTC pudo reconstruir parte de su antigua organización.

Pero bien pronto se reinició la presión sobre las organizaciones que no quisieron encuadrarse en el campo de las lealtades bipartidistas al Frente Nacional. De nuevo la CTC se vió afectada por el anticomunismo que ahora extraía de la Revolución Cubana motivos nuevos e imágenes cargadas de amenazas, aparentemente más próximas.

Se impidió con el apoyo del gobierno liberal de Alberto Lleras Camargo el acceso de los delegados representantes de organizaciones sindicales bajo influencia comunista al XII Congreso de la CTC, que se realizó del 18 al 21 de diciembre de 1960. Se quería por parte de los círculos gubernamentales tener una gran simetría entre la organización del Frente Nacional y los alinderamientos políticos en el seno de los movimientos sociales.

En poco tiempo el empeño de los partidos de contar con su aparato sindical fracasó dando paso a una fragmentación del sindicalismo. En 1964 se conformó, con base en los sindicatos comunistas provenientes de la CTC, una nueva central, la CSTC $(*)$. Esta confederación recibiría el reconocimento jurídico solo 10 años después de creada, en 1974.

Los años sesenta constituyeron un período de incremento de las luchas sociales. El movimeinto huelguístico cobró un notable dinamismo. Se ensanchó el espectro social de quie- nes participaban en cese de actividades. Además de las huelgas en la industria y el transporte, ahora paraban los empleados bancarios, los maestros, los jueces, las enfermeras y los médicos. Se multiplicó tambien el número de organizaciones sindicales. Entre 1957 y 1965 fueron constituidas 1.697 organizaciones sindicales y el volumen de afiliados pasó de 100.000 a 700.000. Sin embargo en el mejor momento del decenio la afiliación a los sindicatos no pasó del 15,4\% de la población ocupada (9).

También en los años sesenta adquirieron presencia en el sindicalismo diversas corrientes políticas de la izquierda radical como el maoismo, el castrismo, el trotsquismo etc., que darían lugar a la constitución de "bloques sindicales independientes". Así se entrelazaron dos lógicas fragmentadoras con respecto al sindicalismo: la del gobierno y la originada en el sectarismo de izquierda. La dispersión le restaba fuerza a los sindicatos para negociar un espacio claro de autonomía y de legitimidad. Ante esta situación el gobierno jugó a la ambiguedad que le permitía combinar represión y reformismo.

Por eso, algunas masacres de obreros que estaban en huelga se dan sin perjuicio de la adopción de decisiones que evocan políticas de concertación: creación del Consejo Nacional del Trabajo (decreto 2210 de 1968) con participación de gobierno, patronos y trabajadores. Nombramiento por el Presidente Carlos Lleras Restrepo de un dirigente sindical como miembro de gabinete. Creación del Banco de los Trabajadores como entidad financiera dirigida por los líderes sindicales. Estas medidas de concertación tenían como destinatario al llamado Sindicalismo democrático", es decir el conformado por la UTC y la CTC, y jugaban como factor de exclusión del resto del movimiento sindical al cual se le presentaba mediante expresiones del siguiente o parecido tenor: "Sindicatos comunistas", "líderes castristas", "infiltración foránea", "Organismos subversivos" "enemigos de las instituciones', La pareja concertación-exclusión formó el mecanismo de la política sindical y obrera, en general, del Frente Nacional .

Al comenzar el decenio de los setenta todavía continuaba la división de la organización sindical: dirigentes obreros con simpatías democristianas crearon una pequeña confederación: la CGT, en mayo de 1971.

Esta etapa que hemos denominado de legitimación precaria se extiende hasta 1977. En ese año se produjo el acontecimiento de protesta social y política más importante que haya dirigido el sindicalismo en Colombia: el Paro Cívico Nacional del 14 de septiembre de 1977 (10).

La política diferenciada del gobierno hacia el sindicalismo se agotó. La concertación y las prebendas hacia los líderes obreros progobiernistas tropieza con límites en un

\footnotetext{
(*) Los partidos pactaron la alternación de liberales y conservadores en la presidencia de la República por un período de 12 años que luego fue ampliado, al tiempo se distribuian por mitad los cargos públicos y la composición de los organismos de representación pupular.

(*) Central Sindical de Trabajadores de Colombia

(9) Ver Hernando Gómez Buendía, Guillermo Perry y Rocío Londoño. El Sindicalismo y la Política Económica. FEDESARROLLO, 1985. pag 271.

(10) Una descripción del paro cívico nacional de 1977 y un análisis de las condiciones históricas en que se produjo se encuentran en el libro de Medófilo Medina. La Protesta Urbana en Colombia en el siglo Veinte. Ediciones Aurora, Bogotá, 1984. pp. 123-187.
} 
país con un ejercicio así sea restringido de las formas democráticas. Esos límites los establece en buena medida el nivel del descontento general de los obreros con la política de gobierno. Hacia 1977 el acumulado de la insatisfacción era notable. En general se admitía el empeoramiento de las condiciones de vida de 1 os trabajadores. La participacion de la remuneración del trabajo en el ingreso nacional había descendido entre 1967 y 1977. Tal participación era del 45.4\% en el primero de esos años y fue del $39.1 \%$ en el segundo. La inflación se convirtió desde comienzos de la década de los setenta en factor permanente de la economía. Si entre 1968 y 1970 la tasa promedio de la inflación fue de 7.6, ya en 1972 se disparó al 14.8, para llegar en el año del paro cívico nacional al $29.2 \%$.

Cuando los líderes de la CSTC lanzaron a comienzos de 1977 la consigna de realización de un Paro Cívico Nacional contra el gobierno, los dirigentes de los demás sectores sindicales no pudieron permanecer en la indiferencia dada la espontánea acogida que suscitó la propueata entre el trabjador raso. Así, con dificultades, se fue conformando una alianza entre las centrales obreras y sectores importantes del sindicalismo no confederado. Esa alianza, de la cual quedaron algunas corrientes sindicales que se autoexcluyeron, estuvo a la cabeza del paro que no solo implicó un generalizado cese de actividades sino que sacó a las calles a verdaderas multitudes de manifestantes.

Ese movimiento alcanzó algunos triunfos como la elevación del salario mínimo en tres ocasiones durante los ocho meses subsisuientes al paro. Pero quizá lo más perdurable desde el punto de vista de resultados de la protesta del 14 de septiembre de 1977 fue la liquidación de la política de "concertación" como la entendían los gobiernos del Frente Nacional y la pérdida de sentido de los alinderamientos políticos tradicionales del sindicalismo.

\section{LOS AÑOS OCHENTA Y NOVENTA O EL RETROCESO EN EL RECONOCIMIENTO POLITICO Y SOCIAL DEL SINDICALISMO}

En los años ochenta y el comienzo del último decenio del siglo no han soplado para los sindicatos colombianos vientos favorables. Continúa en pie el problema endémico de la baja tasa de sindicalización. El segundo censo sindical realizado en 1984 registraba 873.442 personas afiliadas a sindicatos, el censo de 1990 registró 880.155 sindicalizados. Solo se sindicalizaron 6.713 personas. La tasa de sindicalización para el mismo lapso descendió del 9.3\% a $7.8 \%(11)$.

La impotencia del sindicalismo se evidenció en la ausen- cia de una respuesta frente al ajuste llevado a cabo por el gobierno de Belisario Betancur en 1984-1985 dentro de un esquema muy ortodoxo de fidelidad estricta a la política del FMI. Motivos para una protesta general existieron, baste mencionar solo uno: el salario industrial subió entre 1984 y 1989 sólo en $0.7 \%$.

Procesos de orden objetivo dificultan el avance de los sindicatos. Uno de ellos lo representa la expansión de las categorías de los trabajadores informales que en 1988 representaban el 56\% del empleo nacional (12). Los informales no solo tienen dificultades para sindicalizarse sino que influyen en las actitudes de los trabajadores del sector formal por el efecto de amortiguación que sus ingresos ejercen sobre los obreros del sector moderno. Las modalidades de trabajo de los informales alimentan ilusiones de ascenso personal y debilitan las tendencias a la cooperación y los valores de la solidaridad.

A mediados de los años ochenta muchos trabajadores y gente partidaria de cambios cifraron grandes esperanzas en la creación de una central sindical mayoritaria. En 1986 sobre la base de la disolución de la UTC y de la CSTC y con la participación de sindicatos independientes se formó la CUT (*) que agrupaba a un número mayor de trabajadores que el con,junto de 1 os afiliados a las cuatro centrales. En 1990 la CUT reunía al 57.2\% de la población sindicalizada $(* *)$.

Las esperanzas que se asociaron al surgimiento de la CUT se vieron en parte frustradas. La dirección de esta confederacion ha tenido que invertir tiempo y energías en conjurar la amenaza de ruptura, originada en el sectarismo o en las pretensiones hegemónicas de las diversas fuerzas que la integran y que en política van desde el centro hasta la extrema izquierda, desde sectores afines a los partidos tradicionales hasta agrupaciones simpatizantes con la guerrilla.

Por otro lado la existencia de la CUT ha coincidido con el desarrollo de la Guerra Sucia en el país. En un informe preparado por la CUT se consignaba que el número de sus dirigentes y activistas asesinados o desaparecidos por motivos políticos entre 1986 y julio de 1990 ascendía a 588 personas. Por Guerra Sucia (G.S.) se entiende aquí la labor desarrollada por grupos paramilitares, escuadrones de la muerte y sicarios que practican el exterminio de miembros de partidos de izquierdas, directivos y activistas de organizaciones sindicales y sociales en general, de intelectuales de avanzada. El objetivo principal de la G.S. es el de extender el terror en aquellos sectores sociales dentro de los cuales seleccionan sus víctimas.

Por razones diversas el movimiento sindical se convirtió en blanco de la G.S. Luego del Paro Cívico Nacional del 14 de septiembre de 1977 en círculos de la ultraderecha colombiana

\footnotetext{
(11) Fundación Friedrich Ebert de Colombia FESCOL. Por qué la baja sindicalización en Colombia, Bogotá, 1990 pag 12.

(12) PREALC La Deuda Social en Colombia, 1990.

(*) Central Unitaria de Trabajadores.

(**) Después de la creación de la CUT, sindicatos de la antigua UTC y organizaciones orientadas por el MOIR, grupo prochino, formaron (agosto de 1988) una central que tomó el nombre de Confederación de Trabajadores Democráticos de Colombia, CTDC, que agrupa al 10\% de los sindicalizados. La antigua CTC tiene el 7\%, la CGT el $4 \%$. En sindicatos no confederados persiste el $20 \%$ de los sindicalizados
} 
cundió el temor sobre las posibilidades de acontecimientos impredecibles como el paro. Al tiempo, algunos de los estrategas de la guerrilla llegaron a la conclusión de que había llegado el momento cuando la guerrilla rural y el descontento urbano se debían unir en un movimiento de carácter insurreccional. De momento estimularon la creación de aparatos urbanos para la insurgencia. En la acción represiva de este tipo de organizaciones, las Fuerzas Armadas apelaron a procedimientos extrajudiciales tales como torturas y apremios con el fin de obtener confesiones. En un proceso rápido, la confrontación militar entre guerrilla y Fuerzas Armadas y las lógicas y sentimientos que tal confrontación engendra terminaron contaminando los ámbitos de la lucha política y gremial.

La violencia castigó implacablemente al sindicalismo de ciertas ramas agroindustriales como en el caso de la zona bananera de la región de Urabá. Solo entre 1982 y 1986 , Sintagro, el primer sindicato del banano, vió caer asesinados a 350 personas, entre dirigentes y activistas. Desde el año de 1988 se produjeron masacres de trabajadores en la misma región. Igualmente en el norte del país en la produccion de aceite vegetal, el sindicato de la empresa INDUPALMA resultó reducido por el exterminio de 25 de sus afiliados. Los trabajadores de la rama del cemento y la empresa petrolera del Estado, ECOPETROL, resultaron gravemente afectados por el asesinato de dirigentes sindicales.

La guerra sucia se ha extendido y tecnificado también por el apoyo de los carteles de la droga. El narcotráfico se involucró en la guerra sucia por diversos motivos: 1) por la común presencia con la guerrilla en algunas zonas geográficas, 2) por el choque de intereses con sindicatos agrícolas y campesinos a propósito de las inversiones en compra de tierras, 3) por los métodos del "capitalismo salvaje" a que se asocia la presencia del narcotráfico en las relaciones obrero patronales en zonas de inversión de capitales recién "lavados".

Desde 1984, en diversas regiones los grupos paramilitares, las llamadas "autodefensas", encontraron en los capos del narcotráfico apoyo financiero y preparación técnica, contratada en varios casos con instructores de sicarios israelíes e ingleses.

Fenómenos como el narcotráfico, que tomados desde la perspectiva histórica son recientes, tienen una incidencia muy grande por cuanto encuentran un terreno abonado en la tradicional denegación de derechos de que han sido objeto, los movimientos sociales en Colombia. El estado de ánimo antisindical se revive cuando se declara una huelga en un renglón de la economía o en una empresa importante. En tales ocasiones, voceros de los empresarios, del gobierno e incluso de la Iglesia suelen dar rienda suelta a sus prejuicios antisindicales. Los medios de comunicación en tales ocasiones olvidan su misión de informar para convertirse en tribuna. En 1987, cuando por primera vez se firmaba un acuerdo entre los empresarios del banano y los trabajadores en medio de un proceso en que corrió mucha sangre obrera en Urabá, los militares repetían el estribillo sobre los sindicatos como instrumentos de la guerrilla. El diario bogotano "La República", vocero de un sector del conserva- tismo, comentaba en su edición del 8 de julio de 1987: "Es pernicioso que cada una de las 267 fincas en Urabá tenga su sindicato. Sintagro atenta contra la economía del país al promover las huelgas. Es necesario entonces camibiar de frente de trabajo y evitar que los bananeros nacionales acorralados por el sindicalismo comunista tengan que abandonar los cultivos". El obispo Héctor Rueda ya había declarado el 30 de junio de 1987 que los paros del banano tenían orientación subversiva.

Al repasar el principal diario del país "El Tiempo", se constata cómo ninguna huelga en los últimos 10 años ha contado con la neutralidad del periódico, bien al contrario, en artículos y editoriales se ataca a los huelguistas y se toma por principio el punto de vista de los patronos.

La administración del calificativo de "subversivo" dirigido por personas o entidades influyentes suele tener las más peligrosas consecuencias en un país donde estan activos los dispositivos de la guerra sucia.

No hay espacio para describir y analizar los procedimientos puestos en marcha por el Estado para reprimir los movimientos reivindicativos. Tendría utilidad el repaso de las medidas que el gobierno ha tomado con ocasión de los intentos de paro nacional que se han dado despues de 1977. En tales ocasiones los anuncios y las medidas oficiales han creado un ambiente que evoca más la preparación a la guerra civil que a una protesta de un sector de la población civil.

Algunos rasgos del movimiento huelguístico muestran la situación del sindicalismo en Colombia. En los últimos quince años, en promedio, más de la mitad de las huelgas realizadas han obedecido al rechazo de violación patronal de compromisos ya pactados. Es decir, la mayoría de los huelguistas no planteaba nuevas reivindicaciones sino que trató de mantener condiciones anteriormente logradas. Por otro lado, las huelgas de protesta política (por el derecho a la vida) se han incrementado así:

\begin{tabular}{|c|c|}
\hline Años & $\begin{array}{c}\text { Huelga de Protesta } \\
\text { Política (en \%) }\end{array}$ \\
\hline $1986 \ldots$ & .....8.5 \\
\hline $1987 \ldots$ & …...19.3 \\
\hline 1988. & ...31.6 \\
\hline 1989. &. .28 .1 \\
\hline $1990(*$ & .29 .9 \\
\hline
\end{tabular}

Fuente : Alvaro Delgado: Estadísticas CEIS-INEDO.

* Enero-Junio

No hay razones que permitan pensar que se esté generando una actitud nueva de parte de los representantes del Estado en el tratamiento del sindicalismo y de los conflictos laborales. El Presidente César Gaviria Trujillo acudió al viejo procedimiento de asimilar a los huelguistas a la condición de guerrilleros en los juicios que lanzó a propósito del paro que el 22 de abril de 1992 declaró el sindicato de la empresa estatal de telecomunicaciones. El diario óficialista 
"El Tiempo" resumía así uno de los apartes de la alocución del Presidente en la inauguración de una reunión de gobernadores el 24 de abril: "Gaviria fue enfático al señalar que en el país hay dos caminos claros para lograr la renovación y el cambio: por una parte el democrático, que tiene su mejor síntesis en la presencia de los gobernadores elegidos popularmente, y por otro, el de la violencia y la intimidación, como el que vienen utilizando guerrilleros y sindicalistas" (13). Afirmaciones como esas resultan peligrosamente temerarias en un país donde se desarrolla una guerra sucia endémica. Así, los factores de democratización del país que introdujo la nueva carta constitucional de 1991, no actuarán con respecto al sindicalismo si no se produce un cambio de mentalidad y si no se rescata a los sindicatos de esa zona de interinidad legal y de legitimidad precaria en que han estado por tantos anos.

\section{CONCLUSION}

En resumen puede afirmarse que en la mayor parte de la historia contemporánea de Colombia el Estado y sectores muy influyentes de la sociedad civil han estado muy lejos de la aceptación de la legitimidad y del caracter irreversible en una sociedad moderna del fenómeno sindical. Diversos elementos han contribuido en esa situación. En el presente ensayo se han analizado algunos de ellos en su continuidad histórica.

En este momento la discusión sobre el problema de la conquista de la ciudadanía por parte de los movimientos sociales tiene una gran pertinencia por cuanto como ya se señaló se dispone ahora de un nuevo marco normativo que no se quisiera ver convertido en letra muerta. De manera inmediata es preciso propender para que el Estado de Conmoción interior decretado el 9 de noviembre de 1992 por parte del gobierno para contener la brutalidad de la acción guerrillera y del terrorismo del narcotráfico no se use como en el pasado el Estado de Sitio (articulo 121 de la anterior constitutición) para perseguir a las organizaciones sociales y para reprimir a discreción la lentísima protesta ciudadana.

\title{
RESUMEN
}

En el artículo, Medófilo Medina analiza el proceso de legitimación y deslegitimación del movimiento sindical a través de las diferentes etapas históricas, desde principios de siglo hasta la actualidad, teniendo en cuenta los diferentes factores políticos y sociales que han intervenido. En el momento actual, el autor expresa su preocupación por el "estado de interinidad legal y de legitimidad precaria" en que sigue manteniéndose al sindicalismo, a pesar de la aprobación de la Constitución de 1991, que introdujo importantes factores de democratización en el país.

\begin{abstract}
In this article, Medófilo Medina analyzes the legitimation and dislegitimation syndical movement process along the different historical phases, since the beginning of the twentieth century to more recent years, and taking into account political as well as social factors wich have taken place. At this moment, the author express his preocupation because "the state of interinity and precarious legitimacy" in wich is mainteining the syndicalism, in spite of the new Constitution approved in 1991 wich gave importans factors of democratization to the country.
\end{abstract}

